\title{
Coordinated radar observations of plasma wave characteristics in the auroral $F$ region
}

\author{
R. A. Makarevich and W. A. Bristow \\ Geophysical Institute, University of Alaska Fairbanks, Fairbanks, AK, USA \\ Correspondence to: R. Makarevich (r.makarevich@gi.alaska.edu)
}

Received: 3 April 2014 - Revised: 16 June 2014 - Accepted: 21 June 2014 - Published: 29 July 2014

\begin{abstract}
Properties of decameter-scale plasma waves in the auroral $\mathrm{F}$ region are investigated using coordinated observations of plasma wave characteristics with the Kodiak HF coherent radar (KOD) and Poker Flat Incoherent Scatter Radar (PFISR) systems in the Alaskan sector. We analyze one event on 14 November 2012 that occurred during the first PFISR Ion-Neutral Observations in the Thermosphere (PINOT) campaign when exceptionally good F region backscatter data at $1 \mathrm{~s}$ resolution were collected by KOD over the wide range of locations also monitored by PFISR. In particular, both radar systems were observing continuously along the same magnetic meridian, which allowed for a detailed comparison between the line-of-sight (l-o-s) velocity data sets. It is shown that l-o-s velocity correlation for data points strictly matched in time (within $1 \mathrm{~s}$ ) depends strongly on the number of ionospheric echoes detected by KOD in a given post-integration interval or, equivalently, on the KOD echo occurrence in that interval. The 1-o-s velocity correlations reach $0.7-0.9$ for echo occurrences exceeding $70 \%$, while also showing considerable correlations of $0.5-0.6$ for occurrences as low as $10 \%$. Using the same approach of strictly matching the KOD and PFISR data points, factors controlling coherent echo power are investigated, focusing on the electric field and electron density dependencies. It is demonstrated that the signal-to-noise ratio (SNR) of $\mathrm{F}$ region echoes increases nearly monotonically with an increasing electric field strength as well as with an increasing electron density, except at large density values, where SNR drops significantly. The electric field control can be understood in terms of the growth rate of the gradient-drift waves being proportional to the convection drift speed under conditions of fast-changing convection flows, while the density effect may involve over-refraction at large density values and radar backscatter power proportionality to the perturbation density.
\end{abstract}

Keywords. Ionosphere (auroral ionosphere; ionospheric irregularities; plasma waves and instabilities)

\section{Introduction}

Decameter-scale plasma irregularities within the ionospheric F region are routinely used as tracers of ambient plasma moving with the $\boldsymbol{E} \times \boldsymbol{B}$ drift since their phase velocity $\boldsymbol{V}_{\text {irr }}$ is widely accepted to be the convection velocity $\boldsymbol{V}_{E}$ (Tsunoda, 1988). The Super Dual Auroral Radar Network (SuperDARN) in particular relies on the above equivalence to measure the global plasma convection in both hemispheres using the coherent scatter radar (CSR) technique (Greenwald et al., 1995; Chisham et al., 2007). The relationship between irregularity phase and ambient plasma velocities has been the focus of numerous investigations that predominantly employed comparisons with the $\boldsymbol{V}_{E}$ measurements by incoherent scatter radar (ISR) systems (Villain et al., 1985; Ruohoniemi et al., 1987; Davies et al., 1999; Xu et al., 2001; Gillies et al., 2010; Bahcivan et al., 2013) and low Earth-orbit satellites (LEO) (Drayton et al., 2005; Gillies et al., 2009). The overall agreement has been demonstrated with typical correlations of 0.7-0.9 (e.g., Drayton et al., 2005; Gillies et al., 2010). The more recent studies have employed revised velocity estimates considering the refractive index in the scattering volume, which significantly improved agreement in slopes of the linear fit (Gillies et al., 2009, 2010).

The agreement between the irregularity and convection velocities has also been shown to depend, in part, on spatial variations within the SuperDARN and ISR data sets. Thus the agreement has been demonstrated to considerably improve for data sets with a greater degree of spatial homogeneity (Gillies et al., 2010), as expected for SuperDARN and ISR scattering volumes of significantly different sizes. On 
occasion, E region backscatter may also contaminate $\mathrm{F}$ region data sets which can lead to much smaller Doppler velocities observed by SuperDARN (Chisham and Pinnock, 2002; Makarevich, 2008, 2010; Bahcivan et al., 2013).

The overall quality of the SuperDARN measurements is expected to depend on the availability of irregularities in the scattering volume and on backscatter power $P$ or the signalto-noise ratio (SNR) received by the radar. The ISR technique is similar in this regard and the ISR signal intensity is directly controlled by the background electron density $N_{\mathrm{e}}$ conditions within the scattering volume: SNR $\propto N_{\mathrm{e}}$ (e.g., Rishbeth and Williams, 1985). The density control of coherent power $P$ is less direct and the relationship between SNR of coherent backscatter and $N_{\mathrm{e}}$ is far from being established (e.g., Danskin et al., 2002; Kane et al., 2012). One consideration is magnetic aspect angle conditions, since power peaks strongly in a direction perpendicular to the local magnetic field line (zero off-perpendicular aspect angle). Thus backscatter power and backscatter occurrence are expected to depend on refraction, which, in turn, is controlled by the density, so both under-refraction and over-refraction cases are possible (Milan et al., 1997; Danskin et al., 2002; Kane et al., 2012). In addition, higher absorption will also reduce echo power and occurrence. On the other hand, the irregularity intensity may depend on the vector quantities of convection velocity $\boldsymbol{V}_{E}$ (or, equivalently, electric field $\boldsymbol{E}$ ) and electron density gradient $\nabla N_{\mathrm{e}}$. The convection and gradient factors are important because they control the growth rate of the gradient-drift instability (GDI) which is believed to be the primary plasma structuring mechanism in the auroral $F$ region (Tsunoda, 1988). One has to emphasize that, while the $V_{E}$ control of $P$ is expected, experimentally, no clear relationship was found (Danskin et al., 2002).

Ultimately, both relationships $\boldsymbol{V}_{\text {irr }}\left(\boldsymbol{V}_{E}\right)$ and $P\left(\boldsymbol{V}_{E}, N_{\mathrm{e}}\right)$ are related since the experimental ability to establish the former depends on coherent radar data quality which depends on the latter, as discussed above. Establishing these relationships is important for our understanding of both fundamental GDI structuring processes and more applied propagation effects in coherent scatter technique. Previous experimental investigations in this area cited above focused on SuperDARN conjunctions with the European Incoherent Scatter (EISCAT), Sondrestrom, and Resolute Bay ISR facilities, with the efforts to match the measurements often being limited by experimental modes employed. With these limitations, the closest conjunctions were found (typically within $1-5 \mathrm{~min}$ ), that is, not necessarily matched exactly (e.g., within $1 \mathrm{~s}$ ) even in the time domain. A typical experimental configuration also involved analysis of data in field-aligned ISR beams, with meridional context not considered.

In this study, we analyze measurements of the F region coherent echo power and velocity with the SuperDARN radar in Kodiak, Alaska (KOD), in conjunction with the Poker Flat Incoherent Scatter Radar (PFISR) during the first PFISR Ion-Neutral Observations in the Thermosphere (PINOT) campaign. The event under study of 14 November 2012 was characterized by nearly continuous $\mathrm{F}$ region backscatter observed over a $2 \mathrm{~h}$ period within the PFISR viewing area. In addition to standard SuperDARN data at $3 \mathrm{~s}$ integration and $60 \mathrm{~s}$ cadence, KOD provided the data at $1 \mathrm{~s}$ resolution in one beam that was aligned with a meridional PFISR beam. These observations provided an excellent opportunity to re-examine the $\boldsymbol{V}_{\text {irr }}\left(\boldsymbol{V}_{E}\right)$ and $P\left(\boldsymbol{V}_{E}, N_{\mathrm{e}}\right)$ relationships using strict data matching in time, while also addressing the spatial-match aspect by conducting cross-analysis between different latitudinal bins. The specific objectives of the current study are (1) to investigate the relationship between the $\mathrm{F}$ region irregularity velocity and PFISR convection velocity, and (2) to reexamine the convection velocity and electron density control of the coherent echo power using coordinated radar measurements during the PINOT campaign.

\section{Experiment description}

In this study, we analyze the SNR and Doppler velocity data from the SuperDARN KOD radar located in Kodiak, Alaska, US $\left(57.6^{\circ} \mathrm{N}, 152.2^{\circ} \mathrm{W}\right.$; with boresight of $30^{\circ} \mathrm{W}$ of geographic N). This radar is similar to other SuperDARN radars, technically and operationally, as described by Greenwald et al. (1995) and, more recently, by Chisham et al. (2007). In its standard mode of operation, KOD scans through 16 azimuthal directions (radar beams $0-15$ ). The radar measures a 17-lag auto-correlation function from which estimates of the Doppler velocity, power, and spectral width of ionospheric echoes in 75-100 range bins for each radar beam are obtained. The measured Doppler velocity corresponds to the line-of-sight (1-o-s) irregularity velocity and is, by convention, positive for irregularities propagating towards the radar. The range gate length is usually $45 \mathrm{~km}$, with the first range gate at $180 \mathrm{~km}$.

Similar to some other newer SuperDARN radars, KOD is also capable of running in a "stereo" mode and providing observations from two channels, one set of observations from Channel A and the other from Channel B. During the first PINOT campaign in November 2012, Channel A was running as in the standard mode, while Channel B was fixed on beam 3 only (no scanning), a meridional direction towards PFISR. As a result, KOD (Channel B) observations were obtained in this one direction only, but at $1 \mathrm{~s}$ resolution. This allowed us to post-integrate KOD data in Channel B using PFISR integration periods, so that KOD and PFISR data are matched in time within $1 \mathrm{~s}$.

Figure 1a shows, with the blue (red) color, the ionospheric footprint of the KOD field-of-view (FoV) computed using the standard (new) SuperDARN virtual height model (Chisham et al., 2008) up to a range of $1440 \mathrm{~km}$. The selected KOD ranges are shown by the circular arcs, while straight lines show KOD beams $0-15$. Beams $0,3,6,9,12$, and 15 are marked with digits near a range of $1440 \mathrm{~km}$. 

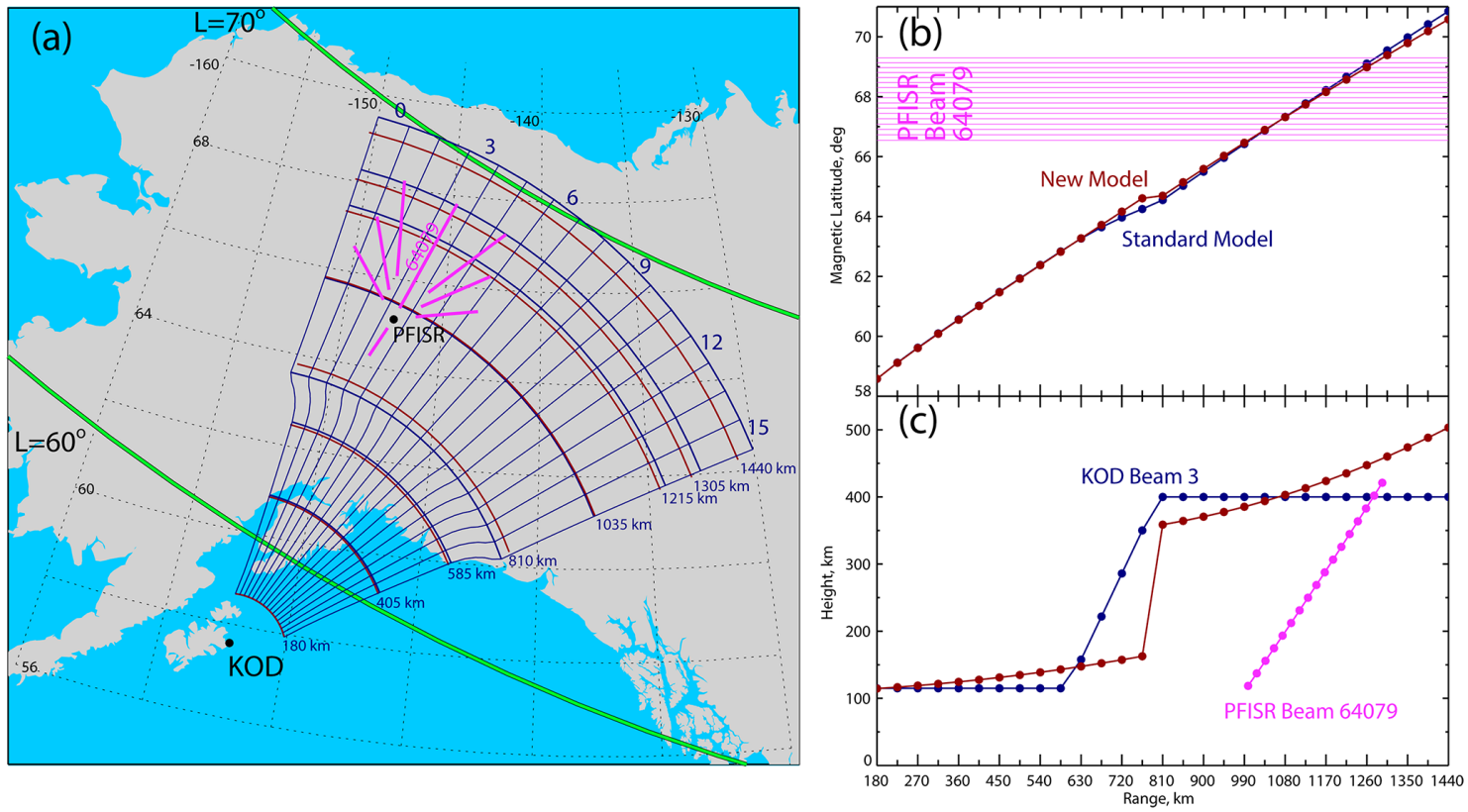

Figure 1. (a) Experiment setup diagram showing the near-range $(<1440 \mathrm{~km})$ geographic footprint of the SuperDARN Kodiak radar (KOD) computed using the standard SuperDARN virtual height model (blue lines). The circular arcs show the start locations of selected range gates and straight lines show all 16 beams with beams $0,3,6,9,12$, and 15 indicated by digits near range $1440 \mathrm{~km}$. The curved red lines are geographic locations of the same range gates computed using a new virtual height model by Chisham et al. (2008). Also shown are the beams of the Poker Flat Incoherent Scatter Radar (PFISR) corresponding to range gates with the long pulse data (thick pink lines) and lines of equal magnetic latitudes $\Lambda=60^{\circ} \mathrm{N}$ and $\Lambda=70^{\circ} \mathrm{N}$ computed using the altitude adjusted corrected geomagnetic (AACGM) model at an altitude $400 \mathrm{~km}$ (green lines). The PFISR beam 64079 is indicated by the digits. The two panels on the right show the (b) AACGM magnetic latitude and (c) virtual height versus KOD range for the standard (blue) and new (red) virtual height models. The pink lines and dots represent range gates in PFISR beam 64079.

The two right panels of Fig. 1 show the magnetic latitude (MLAT; panel b) and virtual height versus slant range in KOD beam 3 for the two models (panel c). All MLAT values were computed using the altitude adjusted corrected geomagnetic (AACGM) model, an extension of the Polar Anglo-American Conjugate Experiment model (Baker and Wing, 1989). The transition between the $\mathrm{E}$ and $\mathrm{F}$ region backscatter is more gradual in the standard model in Fig. 1b, while outside of this region the virtual height is fixed at $115 \mathrm{~km}$ (short ranges) and $400 \mathrm{~km}$ (farther ranges). In Fig. 1a the differences between blue (standard model) and red (new model) circular arcs are small near Poker Flat, but they become somewhat larger at farther and shorter ranges. In the MLAT interval of interest shown by the horizontal pink lines in Fig. 1b, these differences result in a small shift in nominally conjugate locations (by up to one PFISR gate).

The PFISR facility is located at the Poker Flat Research Range $\left(65.13^{\circ} \mathrm{N}, 147.47^{\circ} \mathrm{W}\right.$; MLAT $\left.=65.4^{\circ} \mathrm{N}\right)$ near Fairbanks, Alaska (Heinselman and Nicolls, 2008) (Fig. 1a). PFISR is a phased-array system with narrow beam that can be steered electronically in many directions within the viewing area. Data from multiple beams can be collected nearly simultaneously (sequentially on a pulse-by-pulse basis, but with a very high time cadence) within the same integration period. During the period of interest at 00:0004:00 UT (11:00-15:00 MLT) on 14 November 2012 PFISR operated in the special mode PINOT Daytime31 designed for PINOT daytime studies, a variation of the 13-beam Time History of Events and Macroscale Interactions during Substorms (THEMIS) mode THEMIS31 used for substorm studies (Lyons et al., 2009).

Figure 1a shows footprints of all 13 beams of PFISR with the pink lines. Since all meridional beams point in the same direction, they appear as one line. The beam 64079 that overlaps KOD beam 3 the most is marked by digits. It has an azimuth of $20.5^{\circ} \mathrm{E}$ of geographic $\mathrm{N}$ and elevation of $76.0^{\circ}$. In Fig. 1b, this beam is shown as pink straight lines marking MLATs of each PFISR range gate. In Fig. 1c, the altitudes of all range gates are also shown for PFISR beam 64079.

In most modes, including PINOT, PFISR uses 2 sets of interleaved pulses: a long pulse (LP) with $72 \mathrm{~km}$ range resolution designed for $\mathrm{F}$ region studies and an alternating code (AC) pulse with $4.5 \mathrm{~km}$ resolution used for $\mathrm{E}$ region studies. In this study, we employed the LP data for the electron density and ion drift velocity as well as the convection speed $V_{E}$ estimates. The ion velocity measured in each gate is, by convention, positive for ions propagating away from the radar. The $V_{E}$ estimates are obtained from ion velocities using a 
method described by Heinselman and Nicolls (2008). The 3$\mathrm{D}$ electric field vectors are obtained from the ion drift components in LP gates above $150 \mathrm{~km}$ in altitude by fitting and binning in MLAT; these estimates are most accurate close to the meridional beams including beam 64079. For both PFISR density and velocity the integration period was $1 \mathrm{~min}$. The data in the first two MLAT bins were not considered as those bins had large errors in $V_{E}$ because of the pointing geometry of ion drift velocity vectors that fall into those bins.

\section{Event overview}

The KOD range gates coincident with the PFISR poleward beams, including beam 64079 of interest, all refer to F region backscatter observations (Fig. 1c). At these ranges events with nearly continuous backscatter observations are relatively rare. To determine how typical the event under study was, the echo occurrence analysis was conducted in KOD beam 3 for the entire month of November 2012 (not shown here for brevity). The typical occurrence values throughout the day in this period were $15 \%$, with the highest occurrence of 25-35\% observed between 00:00-04:00 UT. To assess the degree to which backscatter was continuous within this interval, the echo occurrence values were also calculated for the hourly intervals on each day in November 2012, and the day of interest was clearly the highest in occurrence out of all 30 days for the $2 \mathrm{~h}$ interval 01:00-03:00 UT, with echo occurrence of $67 \%$. This is more than 2 times the typical value in this period $(30 \%)$ and more than 4 times the typical value over all $24 \mathrm{~h}(15 \%)$, which makes this event particularly well suited for the analysis involving both the PFISR and KOD data.

Figure 2 presents an overview of the event under study on 14 November 2012, 00:00-04:00 UT. It shows MLAT keograms of reversed ion drift velocity in PFISR beam 64079 (panel a), irregularity l-o-s velocity in KOD beam 3 (panel b), KOD SNR in beam 3 (panel c), PFISR convection speed $V_{E}$ (panel d), and PFISR electron density at $350 \mathrm{~km}$ (panel e). The KOD data shown in panels $\mathrm{b}$ and $\mathrm{c}$ were obtained from post-integrating $1 \mathrm{~s}$ resolution data from Channel B of KOD over each PFISR integration interval, as described in Sect. 2. The PFISR density in each MLAT bin in panel e was obtained from interpolated PFISR density data at $350 \mathrm{~km}$ in all beams and the height of $350 \mathrm{~km}$ was chosen to have a good MLAT coverage. The MLAT bin size was $0.25^{\circ}$, that is, the same as that used for $V_{E}$ estimates. The thick vertical lines separate 5 selected periods of interest, with digits on top of panel a indicating these periods.

Figure $2 \mathrm{a}$ and $\mathrm{b}$ shows that KOD and PFISR 1-o-s velocities exhibit strong similarities when the difference in sign convention is taken into account, for example, convection was strongly away from the radars in period 2 (blue plot cells). Some differences are also evident, for example, convection towards the radars in period 3 near MLAT $69^{\circ}$ (red cells) is more evident in the PFISR data than in the KOD data. The velocity differences are examined in more detail in Sect. 4.

Figure $2 \mathrm{c}$ shows a band of coherent echoes that exhibited some meridional motion throughout most of the interval of interest which was most pronounced in period 3 . This was also the period when PFISR observed very similar equatorward motion of the region with enhanced convection $V_{E}>2000 \mathrm{~m} \mathrm{~s}^{-1}$, dark red cells in Fig. 2d. Thus, in period 3 the association between enhanced SNR and $V_{E}$ is evident. However, near the beginning of period 3 (i.e., at 01:15-01:30 UT) and near MLAT $66.5^{\circ}$ another region of enhanced SNR is seen without particularly enhanced $V_{E}$. Importantly however, in the same MLAT-UT interval Fig. 2e shows a very similar crescent-shaped area of enhanced density $\log N_{\mathrm{e}} \approx 11.3 \mathrm{~m}^{-3}$, which suggests that these echoes are due to enhanced density rather than convection.

If one examines Fig. 2c-e now for all 5 selected periods, the following observations can be made about the $P\left(V_{E}, N_{\mathrm{e}}\right)$ relationship. When $N_{\mathrm{e}}$ is too high, SNR is close to zero and no $\mathrm{F}$ region echoes are observed, as for all MLATs for the entire period 1 and progressively more equatorward area during period 2. A similar feature is observed when $N_{\mathrm{e}}$ is low, as for most of period 5. When $N_{\mathrm{e}}$ is moderate and $V_{E}$ is strongly enhanced, SNR is also enhanced, as in period 2 at MLAT $>68^{\circ}$ and at the start of period 5 near MLAT $66^{\circ}$. SNR can also be enhanced at low $V_{E}$ values, as long as $N_{\mathrm{e}}$ is enhanced but below the levels of period 1 and 2. Period 4 is a clear example of this density control as areas with enhanced SNR and $N_{\mathrm{e}}$ (orange and red cells) are very similar in Fig. 2c and e. Overall, one can conclude that the two effects of interest, that is, the convection and density controls of coherent echo power, are both present and that either can be dominant depending on what values the other parameter takes. These two effects are examined in more detail in Sect. 5.

\section{Line-of-sight velocity comparisons}

Section 3 demonstrated that 1-o-s velocity measurements by KOD and PFISR agreed in general, while also exhibiting some differences in detail. One potential complication in comparing these measurements is that the exact location of SuperDARN measurements depends on the mapping model. The presentation of Fig. 2a and $b$ addressed this issue by considering all range/MLAT bins and looking at general trends such as meridional motions. In the next analysis presented in Fig. 3, a similar idea is employed, where we consider several range gates for both radars near the nominally conjugate gates. In this presentation we show joint KOD-PFISR velocity measurements that are exactly matched in space (according to the mapping model) as well as measurements that are slightly mismatched in space to address the question of how possible spatial differences may affect the result 


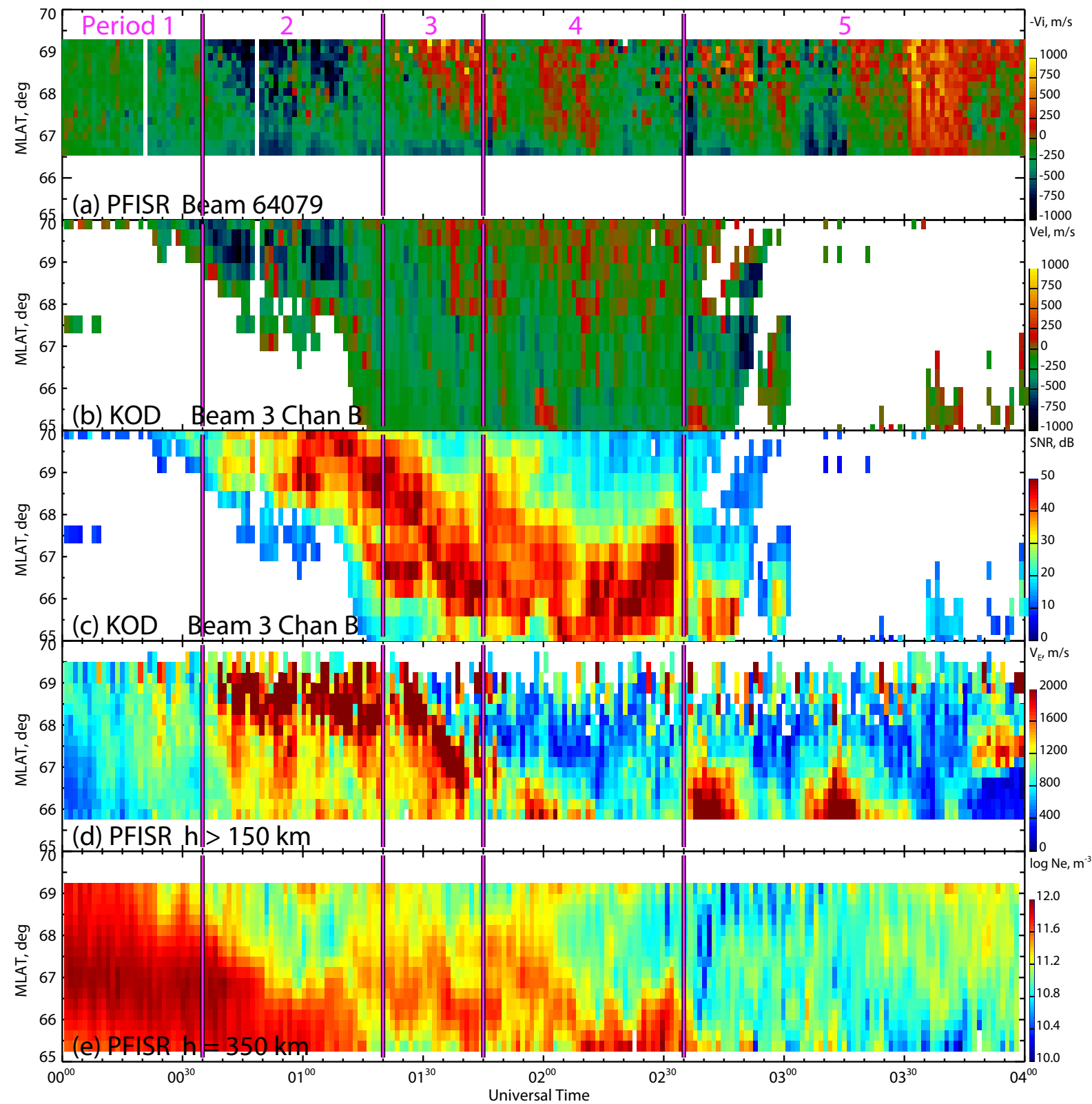

Figure 2. Magnetic latitude keograms of (a) the negative of the line-of-sight (1-o-s) component of the ion drift velocity measured by PFISR in beam 64079; (b) the Doppler velocity measured by KOD in beam 3 and in Channel B and post-integrated over the PFISR integration periods; (c) the KOD signal-to-noise ratio (SNR) in beam 3, Channel B; (d) the PFISR convection drift magnitude $V_{E}$ derived from LP data in all beams; and (e) the PFISR electron density $N_{\mathrm{e}}$ at an altitude of $350 \mathrm{~km}$.

of comparisons. A similar approach is also used in the power analysis, Sect. 5.

Figure 3 shows the point-by-point comparisons between KOD and PFISR velocities for various range gates of PFISR (columns) and KOD (rows). All panels in any given column contain the same PFISR data points and all panels in any given row contain the same KOD data points. The data points included in this analysis were from the entire event (00:0004:00 UT) and the MLAT gates shown here are those that had the longest KOD velocity time series (e.g., see Fig. 2b) and hence largest number of points with both measurements. In the following analysis presented in Fig. 4, most other MLAT gates with measurements were considered. In Fig. 3, the color coding is in KOD SNR and nominally conjugate gates are highlighted by the grey background. The linear Pearson correlation coefficients are given in the bottom-left corner of each panel. The maximum coefficients for each row are shown in red. No additional data filtering of any kind was 


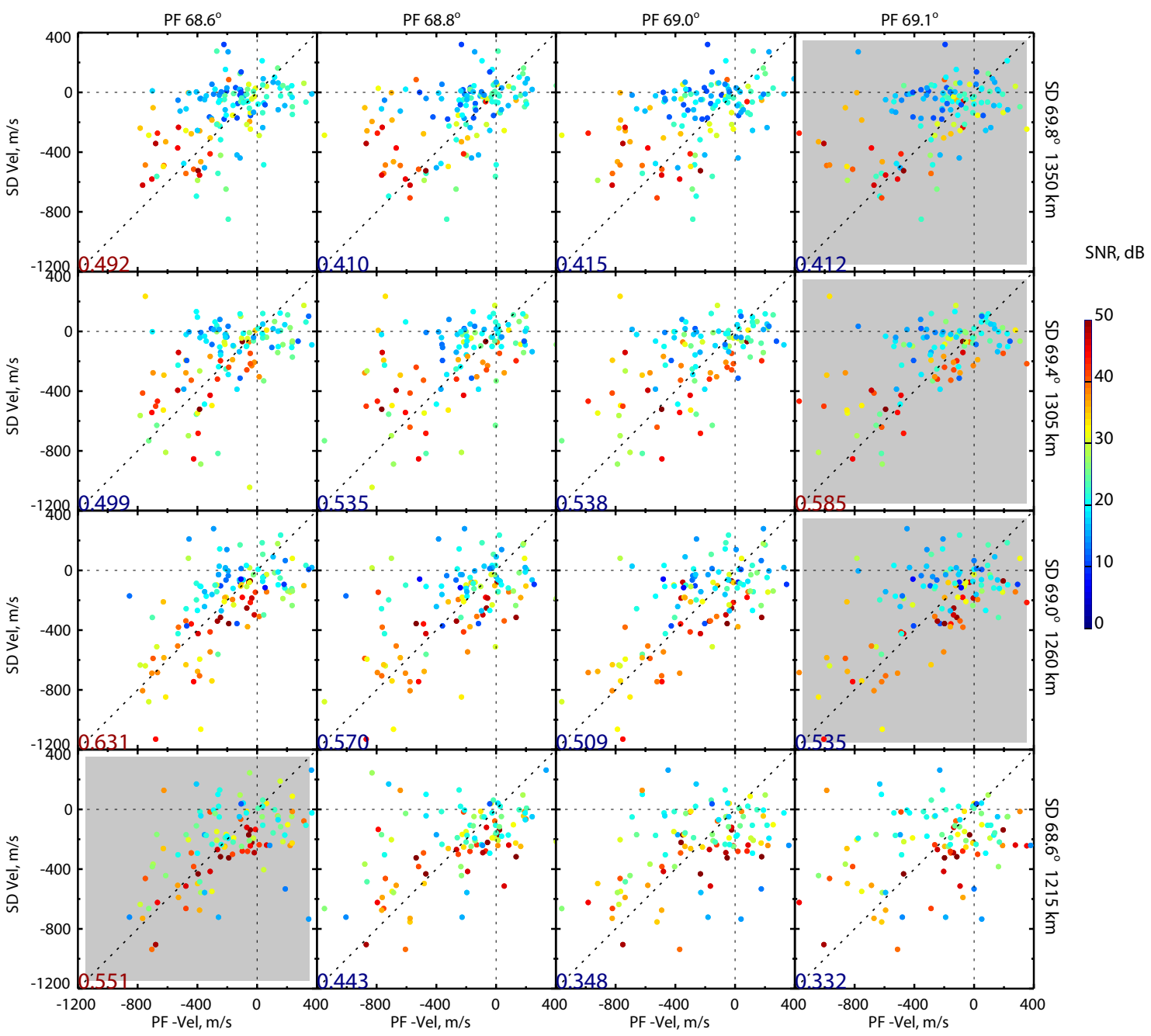

Figure 3. Scatter plots of the SuperDARN KOD Doppler velocity (SD Vel) in beam 3 versus the reversed PFISR ion drift velocity in beam 64079 (PF-Vel). The columns (rows) refer to 4 selected MLATs of the PFISR (KOD) observations as given at the top (right). The points are color-coded in SNR measured by KOD. The digits in the bottom-left corner of each panel show the linear Pearson correlation coefficient between the two velocity data sets. The red digits indicate the maximum correlation for a given KOD range gate (within the PF range gates considered here). The panel highlighted with a grey background refers to the nominally matched MLATs (also within the considered PF gates).

employed here except that we required that at least $10 \%$ of each PFISR integration period contained KOD echoes for each range gate (i.e., $\geq 6$ echoes out of possible 60 in each min). Higher threshold values of 30,50 , and $70 \%$ were also considered, with results presented in Fig. 4.

Despite the minimum amount of requirements, both visual agreement and correlations are reasonable. To be more accurate, the $99 \%$ confidence levels for the data sets shown were $\sim 0.2$, which means that correlations of $0.3-0.6$ were statistically significant. In fact, when one considers echoes with larger SNR values, the agreement appears even better as red points tend to cluster more around the ideal coincidence line. Correlations change within $\sim 20 \%$ of maximum value within the top 3 rows and within $\sim 40 \%$ within the bottom row. For the 2nd and 4th rows, the maximum correlation is observed at the nominally conjugate gate, while for the other two rows it is observed at lower MLAT bins for KOD (by $0.5^{\circ}$ ).

The last observation about Fig. 3 is that there is a large spread of points in each panel. The correlation analysis takes this into account and, for our samples, the correlations were highly significant as discussed above. What correlation analysis does not take into account is uncertainties in individual points. For SuperDARN measurements, these uncertainties are represented by velocity error and, to some extent, spectral width estimates. The errors in individual velocities are usually small and most uncertainty after post-integration comes from velocity standard deviation. It is also generally 


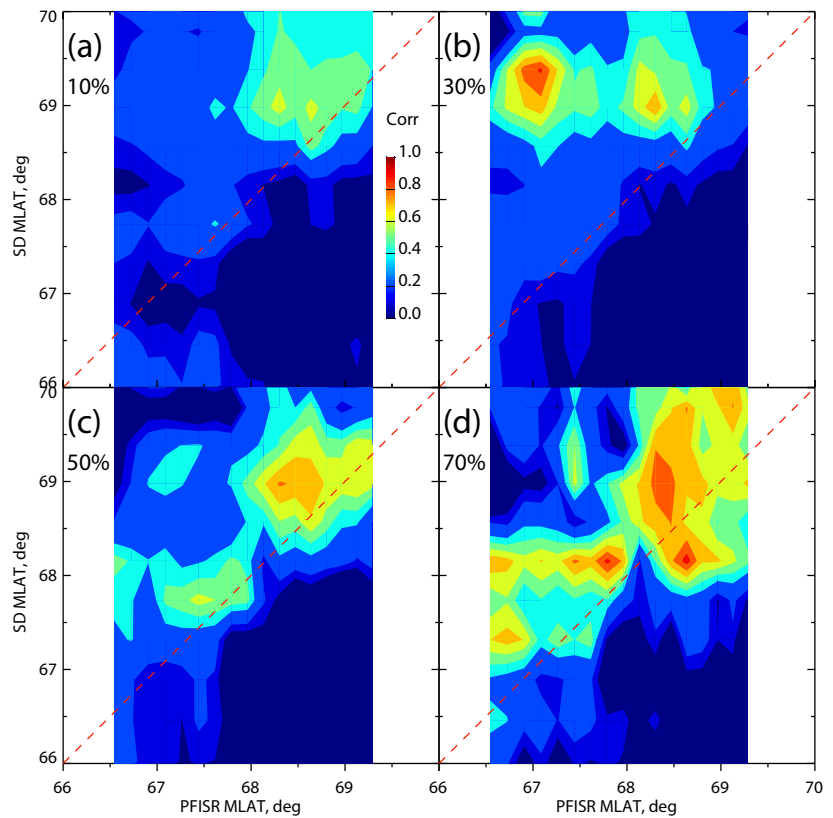

Figure 4. Matrices of correlation coefficients between the KOD and PFISR velocity measurements for various minimum percentage coverage of the PFISR integration periods by KOD (see text for details)

understood that spectral widths exceeding $200 \mathrm{~m} \mathrm{~s}^{-1}$ require careful interpretation, small widths may indicate groundscatter contamination, and typical widths of ionospheric $\mathrm{F}$ region echoes are on the order of $150 \mathrm{~m} \mathrm{~s}^{-1}$ (Ponomarenko and Waters, 2006). Our observations were fully consistent with these general results, as $\sim 50 \%$ of all points had widths of $50-100 \mathrm{~m} \mathrm{~s}^{-1}$ and the other half had widths of 100 $200 \mathrm{~m} \mathrm{~s}^{-1}$, with only a small fraction $(<1 \%)$ having large widths $>200 \mathrm{~m} \mathrm{~s}^{-1}$. The high statistical significance of correlations and the absence of large-error/large-width points gives additional confidence in results presented in Fig. 3.

Figure 4 examines the velocity cross-correlations for broader MLAT intervals. Figure 3 presented only 4 PFISR gates $\times 4$ KOD gates $=16$ points of cross-correlation. Figure 4 now presents $17 \times 13=221$ points. The MLAT gates that were shown in Fig. 3 refer to the top-right portion of Fig. 4a. The different panels a-d show the correlations calculated for different minimum requirements for KOD data coverage of (or, equivalently, KOD echo occurrence during) the PFISR integration intervals. Thus this requirement is the same for Fig. 4a as for Fig. 3, that is, KOD had to observe at least six echoes during each of the $60 \mathrm{~s}$ PFISR integration intervals for this point to be included in the data set and correlation calculation. For panels b, c, and d, this minimum requirement was, respectively, $30 \%$ or 18 echoes, $50 \%$ or 30 echoes, and $70 \%$ or 42 echoes. The dashed diagonal line indicates nominally conjugate locations.
One feature that is immediately obvious in Fig. 4 is generally improving correlations with a MLAT increase. Particularly low and negative correlations are observed below MLAT of $\sim 68^{\circ}$ and to the right of the diagonal line. From Fig. 1, there is nothing particularly special about this MLAT; it is in the middle of the PFISR coverage range and E region range gates $(180-810 \mathrm{~km})$ are at much lower MLATs. Figure $2 \mathrm{~b}$ shows, however, that KOD did not observe many highvelocity echoes below $\sim 68^{\circ}$. Pearson correlations are somewhat sensitive to the range of values, being higher over larger ranges of values for linearly correlated quantities, which may have contributed to low correlation values at these MLATs. It is also possible that the lower correlations simply reflect higher variability of the KOD and/or PFISR measurements at lower MLATs. Correlations are considerably higher at higher MLATs and close to the dashed line of perfect conjugacy; this data subset was shown in Fig. 3.

Figure 4 clearly demonstrates that the correlation progressively improves from panel a to $\mathrm{d}$. Thus for $10 \%$ minimum occurrence in panel a it is $0.5-0.6$ in the top-right corner where peak correlations are observed, while for $70 \%$ in panel $\mathrm{d}$ it is $0.7-0.9$, also in the top-right corner. Improvement is also observed in other parts of the panels (generally to the left of the dashed line). This means that better KOD/PFISR agreement is achieved for greater KOD echo occurrence. A similar analysis was also conducted using progressively larger KOD SNR thresholds instead of percent occurrence (not presented here). A very similar correlation increase was obtained, which is perhaps not surprising since larger echo occurrence usually means larger echo power.

Figure 4 also shows that many contours of significant positive correlation are roughly aligned with the diagonal line of nominally conjugate locations, for example, the contour of 0.4 (green) in panels $\mathrm{c}$ and $\mathrm{d}$. The situation is not as straightforward with contours near maxima, as some KOD range/MLAT bins appear to have larger correlations (e.g., MLAT of $69^{\circ}$ in panel $b$ and MLAT of $68^{\circ}$ in panel d). It is possible that this is due to cross-range interference that is known to be stronger for certain ranges (Ponomarenko and Waters, 2006). Despite this, correlation maxima tend to be near the diagonal line in panels $\mathrm{c}$ and $\mathrm{d}$, which is to be expected if the mapping model works reasonably well. The overall conclusion from this analysis is, therefore, that the higher occurrence or SNR threshold used for velocity comparisons, the better the expected agreement. This may appear to be a trivial (i.e., widely expected) result but, importantly, we show that no evidence of saturation in improvement is seen. This implies that this effect is strong and may, in part, be responsible for the observed correlation improvements from one data set to another when velocity filtering or other improvements are applied. Since power itself is dependent on density and convection velocity, this makes interpreting the results of velocity comparisons particularly challenging. 


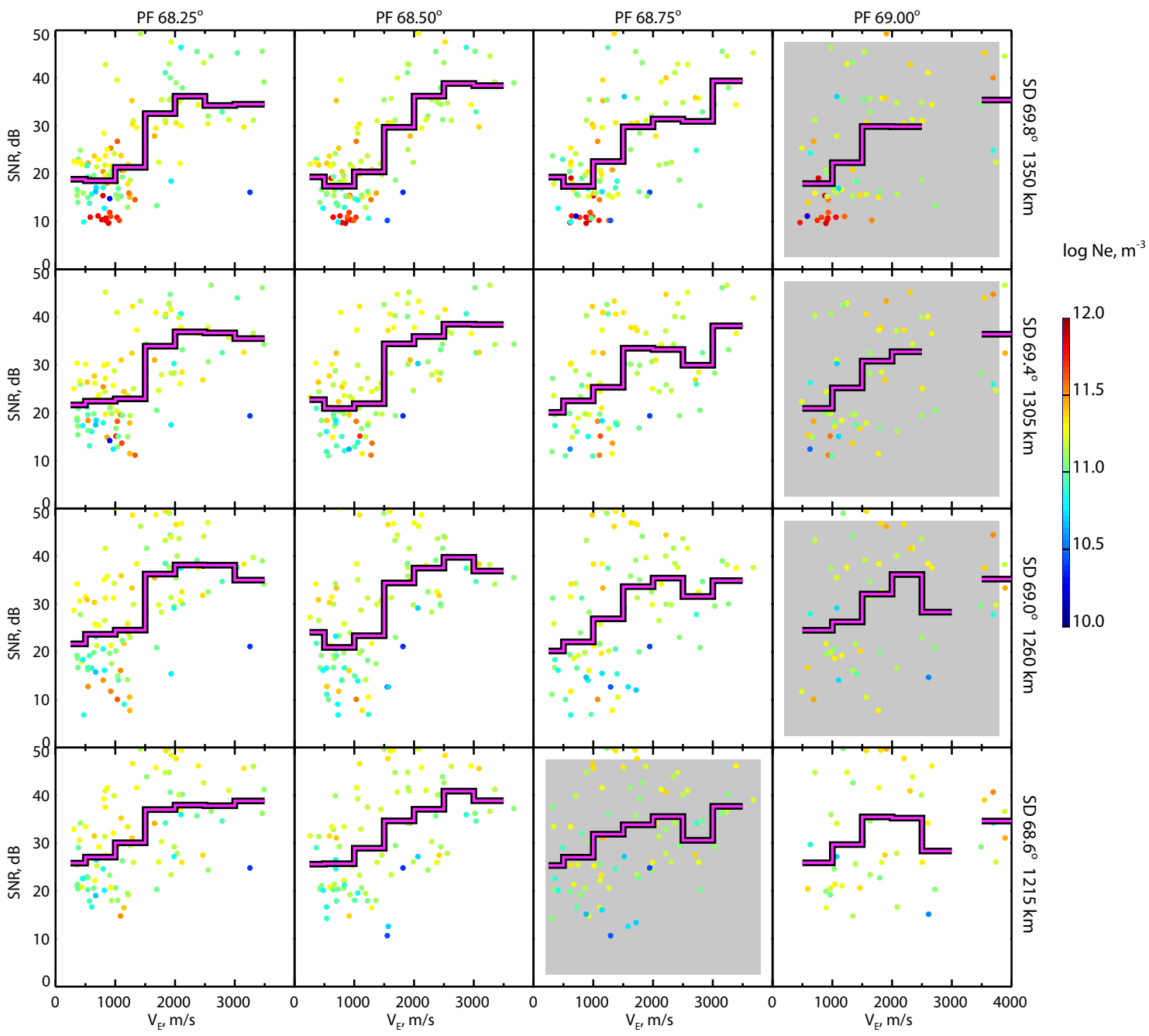

Figure 5. The same as Fig. 3 but for the KOD SNR in beam 3 versus the PFISR convection drift magnitude $V_{E}$. The color coding is in the PFISR electron density $N_{\mathrm{e}}$ at $350 \mathrm{~km}$ (the same as in Fig. 2e). The thick histogram represents the binned data.

\section{Coherent echo power analysis}

As in the previous analysis, we apply a similar approach of considering several MLAT bins near the nominally conjugate locations. Figure 5 shows the KOD SNR versus the PFISR convection speed $V_{E}$. All points are color-coded in the PFISR electron density $N_{\mathrm{e}}$ at $350 \mathrm{~km}$ obtained as described in Sect. 3. MLAT bins used for convection speed $V_{E}$ estimates and interpolated $N_{\mathrm{e}}$ values are different from those used in l-o-s velocity comparisons (which were simply the original PFISR range gates along the specific beam 64079). This is why both MLAT bin sizes and location of conjugate bins are slightly different between Figs. 3 and 5.

The thick black-pink line in each panel of Fig. 5 shows the SNR mean values in $500 \mathrm{~m} \mathrm{~s}^{-1}$ bins in convection speed $V_{E}$; this binned trend increases with $V_{E}$ increasing. The typical uncertainty in these binned values were $7-10 \mathrm{~dB}$ (not shown to keep the diagram readable) so that some of the increase is within uncertainty. Nevertheless, the increase is monotonic, with very few exceptions, which strengthens the argument that it is real. The trend includes all points, at all $N_{\mathrm{e}}$ values. Since it was emphasized previously that these two effects (convection and density) need to be considered separately, if at all possible, better insight would be obtained for trends computed for different levels of $N_{\mathrm{e}}$. Unfortunately, two things make this analysis problematic: (1) a limited overall number of points and (2) some anti-correlation between $V_{E}$ and $N_{\mathrm{e}}$. The second effect is very evident for the top row, where high-density points (red) are only present at low $V_{E}$ values. Nevertheless, one can see that the $P\left(V_{E}\right)$ increase is observed for all points, but also for groups of similarly colored points where such subsets were present for many $V_{E}$ bins, as, for example, for the 2 left columns. The differences between nominally conjugate bins (grey background) and other bins are not large, so that the features identified should be regarded as independent of mapping uncertainties. 


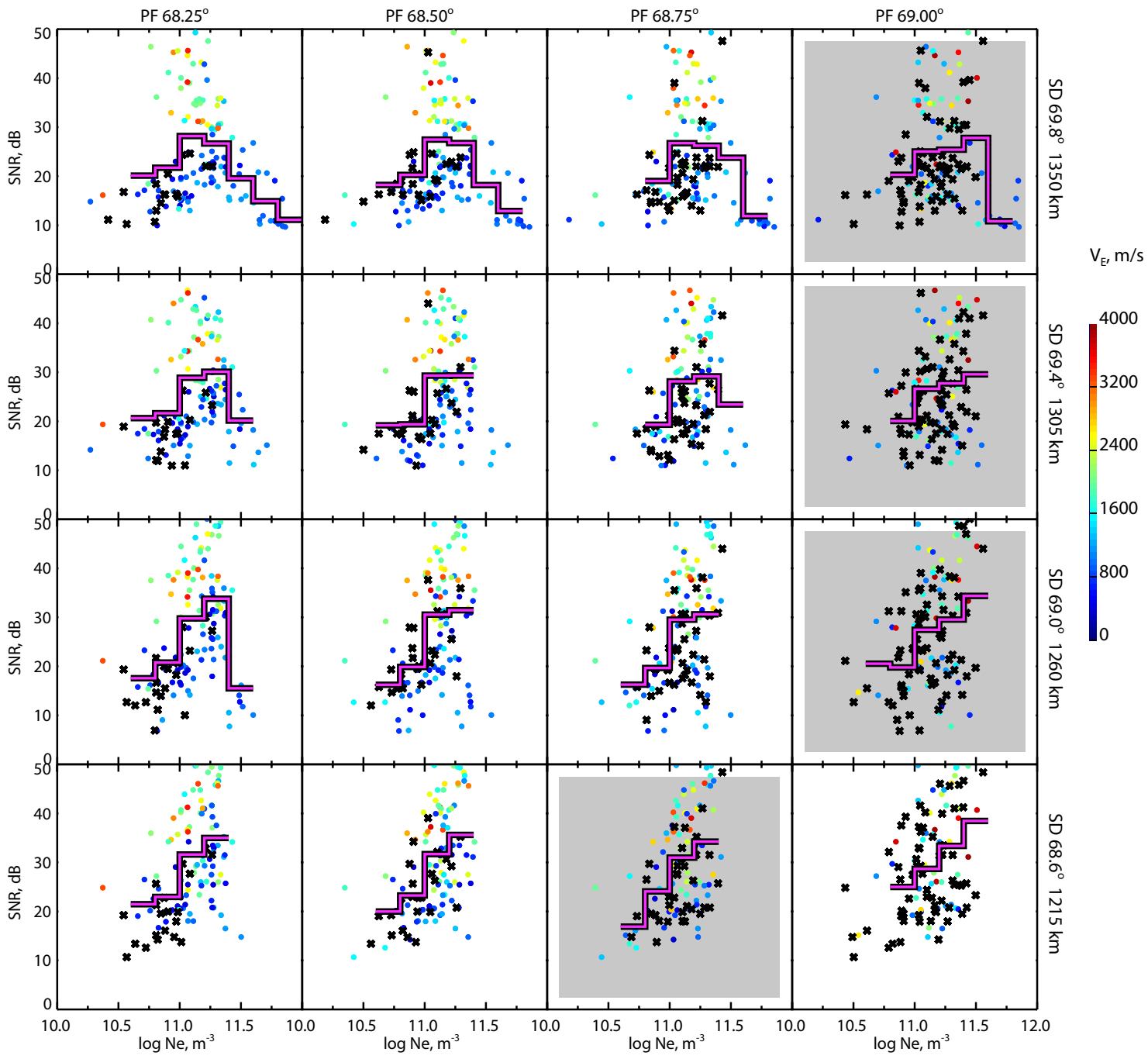

Figure 6. The same as Fig. 5 but versus the electron density $N_{\mathrm{e}}$ and color-coded in the convection drift magnitude $V_{E}$. The black crosses represent the data points without the $V_{E}$ information.

Figure 6 presents the same data as Fig. 55, but with $V_{E}$ and $N_{\mathrm{e}}$ variables swapped (i.e., $\mathrm{SNR}$ is plotted versus $N_{\mathrm{e}}$ and color-coded in $V_{E}$ ). The uncertainties in the binned values were again $7-10 \mathrm{~dB}$. One difference with previous analysis is that here we considered all points with simultaneous SNR and $N_{\mathrm{e}}$ including those that did not have simultaneous $V_{E}$ information; these points are shown by black crosses.

The SNR binned trend does not show a monotonic increase with $N_{\mathrm{e}}$. Instead, it increases up until a value of $\log N_{\mathrm{e}} \cong$ $11.3 \mathrm{~m}^{-3}$, after which it either drops, as in the first 2 rows, or stops due to the lack of high-density points. The reason why high-density points are only present in the first 2 rows is that these were the MLAT bins with high densities and some KOD echoes, period 1 in Fig. 2. In principle, one could attempt to extend the data set by including other high-density points with very low or zero SNR, for example, at MLATs below $68^{\circ}$ in period 1 . It is very clear though, that high $N_{\mathrm{e}}$ values means no echoes or low/zero SNR.

The color structure of the points in Fig. 6 shows the convection effect, as points with higher $V_{E}$ estimates, where available, tend to be higher. This is just another representation of the same monotonic increase $P\left(V_{E}\right)$ that was seen in Fig. 5. The density effect is significantly different; it is monotonically increasing to a value of $\log N_{\mathrm{e}} \cong 11.3 \mathrm{~m}^{-3}$, and then decreasing. This approximate value thus represents the "best" or "ideal" density to observe F region irregularities with the KOD radar near PFISR. Figures 5 and 6 demonstrate fundamental differences between the convection and density effects in coherent echo power; their interpretation is offered below. 


\section{Discussion}

In this study, plasma wave characteristics in the auroral $\mathrm{F}$ region were analyzed using coordinated radar observations with the Kodiak coherent HF radar and PFISR facility in Alaska. The data were collected during the first PINOT campaign during which the two radar systems provided coincident measurements of irregularity and ambient plasma characteristics near PFISR including in the same meridional direction. This allowed us to match the radar data in time within $1 \mathrm{~s}$, while accounting for spatial effects by conducting cross-comparisons between different range gates, in order to investigate the fundamental relationships between the irregularity phase and convection velocity $\boldsymbol{V}_{\text {irr }}\left(\boldsymbol{V}_{E}\right)$ and between the irregularity power, convection velocity, and ambient electron density $P\left(V_{E}, N_{\mathrm{e}}\right)$.

\subsection{Irregularity and convection velocities}

Comparisons between the coincident Doppler velocity measurements by coherent and incoherent radar system have attracted significant research effort in the past, Sect. 1. This analysis is important for verification of the equivalence between the small-scale irregularity velocity and large-scale convection velocity, a principle that enables observations of ionospheric plasma convection dynamics with coherent $\mathrm{HF}$ radars such as SuperDARN. While the equivalence principle itself is widely accepted both from the theoretical and experimental points of view (e.g., see the review by Chisham et al., 2007), detailed analysis results often contain hints as to how to fine-tune radar data processing and analysis methods.

One important point that was recognized early on was different sizes of the radar sampling volume between coherent and incoherent scatter radar techniques (Ruohoniemi et al., 1987; Davies et al., 1999). At typical $1000 \mathrm{~km}$ ranges from the radar site where CSR/ISR comparisons are normally conducted, at standard $45 \mathrm{~km}$ range resolution, and at typical sounding frequencies of $10-12 \mathrm{MHz}$, these sizes in the horizontal plane are on the order of $50 \mathrm{~km} \times 100 \mathrm{~km}$ for coherent versus $5 \mathrm{~km} \times 50 \mathrm{~km}$ for incoherent radar measurements (Ruohoniemi et al., 1987). Thus, while both systems are measuring the same parameter physically (plasma velocity), the plasma parcels they refer to have different scales and can therefore exhibit some differences in velocity at any given time if the plasma flow is highly nonuniform. If the flow is relatively uniform, smaller differences are expected. In large part because of this expectation, various restrictions are often employed in CSR/ISR and CSR/LEO comparative studies such as velocity filtering and selection of uniform-flow events (e.g., Davies et al., 1999; Drayton et al., 2005; Gillies et al., 2009). The other related aspect is possible effects of ground and $\mathrm{E}$ region scatter, both of which can effectively suppress HF radar velocity significantly below the convection component (Davies et al., 1999; Chisham and Pinnock, 2002; Makarevitch et al., 2004). While standard criteria on coherent echo velocity, width, and range eliminate most of ground and E region echoes, additional restrictions have been shown to improve correlations with ISR measurements even further, from $\sim 0.7$ linear correlations to $\sim 0.9$ (Gillies et al., 2009).

In the current study, a somewhat different approach has been employed as described below. First, we focus on observations from Channel B of KOD. In this channel, KOD measurements were collected from one fixed direction only (beam 3) but at $1 \mathrm{~s}$ resolution. This is comparable with typical integration periods of standard SuperDARN modes that have been employed in the past, that is, integrations of $3 \mathrm{~s}$ (fast scan) or $7 \mathrm{~s}$ (normal scan) per beam with all 16 beams scanned in 60 or $120 \mathrm{~s}$. However, the important difference is that no scanning was done on Channel B, which allowed us to post-integrate the KOD data using the same (within $1 \mathrm{~s}$ ) time intervals as those used in the PFISR data analysis. This is in contrast with previous studies that used scanning modes and compared SuperDARN data at 3 or $7 \mathrm{~s}$ integration with 20$100 \mathrm{~s}$ integrations for ISR data (e.g., Davies et al., 1999; Xu et al., 2001). Combined with PFISR ability to also provide quasi-continuous data from a number of directions, including several that were aligned with KOD beam 3 (Fig. 1) this allowed us to strictly match measurements in time. Moreover, characterization of post-integrated KOD data in terms of coherent echo occurrence or power for each post-integrated data point allowed us to investigate the dependence of correlation on these measures related to data quality.

The results of this new analysis showed that the quality of agreement expressed as linear correlation strongly depends on the KOD coverage of PFISR integration periods or, equivalently, on the coherent echo occurrence (Fig. 4). For minimum considered coverage levels of $10 \%$, the correlations were on the order of 0.5 , but rising significantly to $0.7-0.9$ for coverages exceeding $70 \%$ (Fig. 4). Since this whole analysis was based on single-fixed-beam observations in Channel B, it is instructive to compare the results with those based on multiple-beam data from Channel A where no post-integration was possible. These results were largely similar, in that the KOD Channel A velocities also exhibited significant positive correlations with PFISR ion drift velocities. The correlation magnitudes were similar to those in Figs. 3 and $4 a$, but lower than those for higher coverage levels in Fig. $4 \mathrm{~b}-\mathrm{d}$, with the maximum correlations of $0.5-0.6$, that is, lower by $0.2-0.3$ than maximum correlations with KOD velocities in Channel B.

These results indicate that substantial improvements in agreement between the irregularity and convection velocity measurements can be achieved if continuous single-beam velocity measurements are available, for example, from Channel B of "stereo" HF radars. The availability of hightime-resolution continuous measurements for a HF radar means that the measurements from two radar systems can be matched in time exactly (within $1 \mathrm{~s}$ for the current study). 
The important and nontrivial point about the irregularity and convection velocity comparisons is that improved agreement, in general, does not mean improved data quality. One can argue however, that improved agreement would mean improved data quality if one assumes that the irregularity and convection velocity in the $\mathrm{F}$ region must be equivalent, as theory predicts and most observations show. Under this equivalence principle, the greater degree of agreement is, the better the data quality must be. In this context, the current results suggest that improvements in overall measurement quality of coherent echo characteristics can be achieved by using longer integration times. This argument is not restricted to single-beam measurements, but it is those measurements that provide additional opportunities to verify and ultimately rely on the velocity equivalence principle.

A central issue here is also that the measurement quality is not just the values of parameters measured, but also the spatial and temporal intervals they refer to. The present study reinforces the importance of the well-known but sometimes overlooked differences between integration, resolution, and cadence time intervals, by demonstrating the high value and quality of measurements for which integration is conducted over the entire cadence interval. A highly expected but not often demonstrated result here is that integrated measurements would represent this interval better, if more of them come from it.

At the same time, multiple-beam measurements are normally used in SuperDARN since improvements would be achieved at the expense of data statistics. The important new results of the current study were also that no saturation was observed in quality of agreement with increasing coverage/occurrence level and that substantial improvements in agreement do not necessarily require sophisticated data selection procedures. Large magnitudes of improvement and absence of saturation even suggest that strictly matching the data in time may be more important than, say, matching them in space or applying other restrictions.

On the issue of spatial differences between SuperDARN and ISR measurement volumes, one complication is that neither height nor horizontal position is known accurately for SuperDARN measurements as discussed below. The same ionospheric refraction that enables backscatter measurements from the high-latitude $\mathrm{F}$ region, makes the mapping task more challenging at HF frequencies. This was one reason why a new virtual height model has been developed by Chisham et al. (2008) and tested for accuracy by Yeoman et al. (2008) using known locations of artificially generated backscatter. The new model showed substantial improvements, particularly at further SuperDARN ranges. At the $1000-1500 \mathrm{~km}$ ranges of interest both models are accurate within $15 \mathrm{~km}$, as demonstrated by Yeoman et al. (2001) for the standard and Yeoman et al. (2008) for the new model, respectively.

In the current study both virtual height models have been used to calculate geographic positions of HF range gates
(Fig. 1a) and the AACGM model was then used to convert them into geomagnetic coordinates (Fig. 1b). As expected for these ranges, only minor differences were found between the model results, but since PFISR range gates were $\sim 3$ times smaller in MLAT extent than those of KOD, this resulted in slight differences in nominally conjugate gate pairs. To address the issue of spatial differences/uncertainties, the current study considered several range/MLAT bins in the vicinity of nominally conjugate pairs (Figs. 3-6). Since all features of interest were observed in majority of gates with few exceptions, the results of the current study should be regarded as independent of the mapping model and associated uncertainties.

\subsection{Factors controlling coherent echo power}

The other fundamental relationship under investigation was a dependence of coherent echo power or SNR on the convection velocity and electron density $P\left(V_{E}, N_{\mathrm{e}}\right)$. The dependence on the convection velocity $\boldsymbol{V}_{E}$ or, equivalently, on the electric field $\boldsymbol{E}$ is expected from the GDI theory, since the growth rate of GDI waves $\gamma$ is proportional to the magnitude of convection velocity relative to that of the neutral gas or the slip velocity $V_{0}=V_{E}-V_{n}$ (Linson and Workman, 1970; Huba et al., 1983; Keskinen, 1984). In our observations, convection velocities were between $200-4000 \mathrm{~m} \mathrm{~s}^{-1}$ (Fig. 5) and for most of the interval of interest, $V_{E}$ was varying on timescales of 20-30 min (Fig. 2d). In this situation, the neutral winds are very unlikely to respond to ion convection so that to largely cancel variations in $V_{E}$. Previous investigations at similar auroral latitudes demonstrated that neutral winds typically respond to ion convection with a time lag of 30-40 min and do not exceed 200-300 $\mathrm{m} \mathrm{s}^{-1}$ (Kosch et al., 2010). The present observations were conducted during the daytime hours (11:00-15:00 MLT) and no optical measurements of neutral drifts were available. One expects, though, that under these conditions, fast and strong variations in $V_{E}$ should result in similarly fast and strong variations in $V_{0}$ and hence GDI growth rate $\gamma$. While the relationship between the instability growth rate $\gamma$ and backscatter power is far from being straightforward, it is often assumed that higher growth rates result in stronger perturbation densities $\delta N_{\mathrm{e}}$ which, in turn, means stronger backscatter power since $P \propto\left|\delta N_{\mathrm{e}}\right|^{2}$ (e.g., Schlegel, 1996).

The previous experimental efforts, however, were largely inconclusive with respect to the expected convection effect in F region backscatter power. Thus Danskin et al. (2002) found only some increase of power versus electric field up to $E=80 \mathrm{mV} \mathrm{m}^{-1}$ or $V_{E}=1600 \mathrm{~m} \mathrm{~s}^{-1}$. The increase observed by Danskin et al. (2002) was not really monotonic (see their Fig. 8a). The absence of clear results may, in part, be attributed to limited range of available $V_{E}$ values and other competing effects that are difficult to separate from that of $V_{E}$, particularly density-related effects such as absorption and propagation. In this context, the important new result of 
the current study is the convection effects are much more evident for extended $V_{E}$ range of up to $3500-4000 \mathrm{~m} \mathrm{~s}^{-1}$ (Fig. 5). In addition, simultaneous consideration of density and convection velocity aided in separating these effects, even though the separation was not complete, due to limited statistics and $V_{E}-N_{\mathrm{e}}$ anticorrelation, as was discussed in Sect. 5. The present study thus strengthens the notion of the backscatter power being affected by convection strength in support of the above theoretical argument. In particular, the results are largely consistent with the notion of perturbation density increasing with the convection electric field. This is a relatively well-established result in the $\mathrm{E}$ region (e.g., Haldoupis et al., 1984, 1990), but not in the F region, where experimental evidence is largely lacking.

A closely related effect is power dependence on the background electron density $N_{\mathrm{e}}$. One aspect of the problem is propagation conditions. One expects these conditions to be unfavorable for both low and high density values since a radar beam would not reach orthogonality with a magnetic field. This is precisely what has been observed in the present study (Figs. 2 and 6). These effects are well known and often discussed in HF radar studies focusing on occurrence and/or power analysis of $\mathrm{F}$ region irregularities (Milan et al., 1997; Danskin et al., 2002; Koustov et al., 2004).

There is potentially one other effect, however, that received much less attention and that may have contributed to the trends observed in the current study. This effect involves background density indirectly affecting the perturbation density as explained below. The key question here is if and how the instability processes affect the fractional density $\delta N_{\mathrm{e}} / N_{\mathrm{e}}$ rather than the perturbation density $\delta N_{\mathrm{e}}$ itself. The answer to this question is largely unknown for the $\mathrm{F}$ region irregularities. It has been suggested however, that for their $\mathrm{E}$ region counterparts, the fractional density is controlled by the electric field $E$ or by the convection speed $V_{E}$ (e.g., Kustov et al., 1988; Haldoupis et al., 1990; Schlegel, 1996), so that

$P\left(V_{E}, N_{\mathrm{e}}\right) \propto\left|\delta N_{\mathrm{e}} / N_{\mathrm{e}}\right|^{2} N_{\mathrm{e}}^{2}=f\left(V_{E}\right) N_{\mathrm{e}}^{2}$,

where $f\left(V_{E}\right)$ is some function of the convection speed. For the $\mathrm{E}$ region several possible dependencies $f\left(V_{E}\right)$ have been suggested, while in the $\mathrm{F}$ region the effect remains largely uninvestigated.

In our observations, the $\mathrm{F}$ region backscatter power was shown to increase with $N_{\mathrm{e}}$ up until a certain value near $\log N_{\mathrm{e}}=11.3 \mathrm{~m}^{-3}$ (Fig. 6). This was observed for both all points considered (i.e., for all $V_{E}$ values) and for subsets of points with the same $V_{E}$ values where such subsets were large enough (blue points in Fig. 6). Hence, one can interpret the observed increase $P\left(N_{\mathrm{e}}\right)$ as being due to the power control by the $N_{\mathrm{e}}^{2}$ factor in Eq. (1) in the situation when convection variations are small and $f\left(V_{E}\right) \approx$ const. Of course when convection variations are significant, their effect is to increase power for larger $V_{E}$ values, as was also demonstrated in the current study. For example, for the group of points near $\log N_{\mathrm{e}}=11.3 \mathrm{~m}^{-3}$ in Fig. 6, the power increase with $N_{\mathrm{e}}$ is stronger than it would be in the absence of any variations in $V_{E}$. Importantly though, not all of the increase in power near this value is due to an increase in $V_{E}$, since an increase is clearly observed for only blue points in Fig. 6 . One can thus argue that the power increase with background density is, at least to some extent, due to the indirect effect described above.

The current study has attempted to experimentally separate the background density effects from those of the convection velocity in the F region echo power and Eq. (1) can be viewed as one way to summarize two results of this investigation: (1) that these groups of effects are separable and (2) that the dependence on convection velocity $f\left(V_{E}\right)$ is monotonic and with little evidence of saturation.

Besides convection velocity and background density, the $F$ region backscatter power may be affected by the conductance of the underlying E region (Vickrey and Kelley, 1982). This effect is due to shorting of perturbation electric fields through highly conducting E layer. The experimental evidence for this effect remains inconclusive (Danskin et al., 2002; Kane et al., 2012), and unfortunately the current experimental configuration did not allow us to shed any further light on it. PFISR is one of the few instruments that can provide high-quality data on density and hence conductance. However, the PFISR E region ranges only extend up to MLAT of $66.5^{\circ}$ (3 first pink lines in Fig. 1b), thus overlapping only the first 3 range gates of PFISR in Fig. $2 d$ and only 2 conjugate ranges of KOD in Fig. 2b-c. In the current event these were most uninteresting gates, with fewer joint points and very few points with large density values (e.g., Fig. 5), so that a simultaneous investigation of three competing effects was not possible.

\section{Summary and conclusions}

Analysis of coordinated radar observations of plasma wave characteristics in the auroral $\mathrm{F}$ region showed that

1. Agreements between 1-o-s velocities measured using coherent and incoherent radar techniques improves drastically when data points are strictly matched in time (within $1 \mathrm{~s}$ ) and when progressively stronger restrictions are introduced on the number of ionospheric echoes detected by a coherent radar in a given analysis interval or, equivalently, on its coverage of this interval. No saturation is observed in improvement as measured in linear correlations for progressively stronger restrictions, which suggests that simultaneity in time is one of the main factors that control the quality of agreement. This strengthens the notion of small-scale F region irregularities serving as tracers of large-scale plasma convection. Under the assumption of equivalence between the convection and irregularity velocities, it also provides an alternative way to ensure the high quality of Doppler velocity data. 
2. The F region backscatter power increases nearly monotonically with convection speed or, equivalently, with the electric field magnitude, with little evidence of saturation at the highest observed convection drifts near $3500 \mathrm{~m} \mathrm{~s}^{-1}$. This result is consistent with the irregularity growth rate increase with convection speed expected from the linear theory of the gradient-drift instability. The power is also controlled strongly by the background density. The density effect is nonlinear with the peak power observed near $\log N_{\mathrm{e}}=11.3 \mathrm{~m}^{-3}$. The power increases with density in the density range below this value, which is likely due to under-refraction affecting propagation and aspect conditions. Similarly, the power decrease above this critical value is likely to be due to over-refraction. The power increase at lower density values may also be due to an indirect density effect involving radar backscatter power proportionality to both fractional perturbation density and background density factors.

Acknowledgements. This research was supported by NSF grants AGS-1243476, AGS-1242913, and AGS-1069024. The Poker Flat Incoherent Scatter Radar is operated by SRI International on behalf of the US National Science Foundation under NSF Cooperative Agreement AGS-1133009.

Topical Editor K. Hosokawa thanks two anonymous referees for their help in evaluating this paper.

\section{References}

Bahcivan, H., Nicolls, M. J., and Perry, G.: Comparison of SuperDARN irregularity drift measurements and F-region ion velocities from the Resolute Bay ISR, J. Atmos. Sol.-Terr. Phys., 105, 325-331, 2013.

Baker, K. B. and Wing, S.: A new magnetic coordinate system for conjugate studies at high latitudes, J. Geophys. Res., 94, 91399143, 1989.

Chisham, G. and Pinnock, M.: Assessing the contamination of SuperDARN global convection maps by non-F-region backscatter, Ann. Geophys., 20, 13-28, doi:10.5194/angeo-20-13-2002, 2002.

Chisham, G., Lester, M., Milan, S. E., Freeman, M. P., Bristow, W. A., Grocott, A., McWilliams, K. A., Ruohoniemi, J. M., Yeoman, T., Dyson, P. L., Greenwald, R. A., Kikuchi, T., Pinnock, M., Rash, J. P. S., Sato, N., Sofko, G. J., Villain, J.P., and Walker, A. D. M.: A decade of the Super Dual Auroral Radar Network (SuperDARN): scientific achievements, new techniques and future directions, Surv. Geophys., 28, 33-109, doi:10.1007/s10712-007-9017-8, 2007.

Chisham, G., Yeoman, T. K., and Sofko, G. J.: Mapping ionospheric backscatter measured by the SuperDARN HF radars - Part 1: A new empirical virtual height model, Ann. Geophys., 26, 823841, doi:10.5194/angeo-26-823-2008, 2008.

Danskin, D. W., Koustov, A. V., Ogawa, T., Nishitani, N., Nozawa, S., Milan, S. E., Lester, M., and Andre, D.: On the factors con- trolling occurrence of F-region coherent echoes, Ann. Geophys., 20, 1385-1397, doi:10.5194/angeo-20-1385-2002, 2002.

Davies, J. A., Lester, M., Milan, S. E., and Yeoman, T. K.: A comparison of velocity measurements from the CUTLASS Finland radar and the EISCAT UHF system, Ann. Geophys., 17, 892902, doi:10.1007/s00585-999-0892-9, 1999.

Drayton, R. A., Koustov, A. V., Hairston, M. R., and Villain, J.-P.: Comparison of DMSP cross-track ion drifts and SuperDARN line-of-sight velocities, Ann. Geophys., 23, 2479-2486, doi:10.5194/angeo-23-2479-2005, 2005.

Gillies, R. G., Hussey, G. C., Sofko, G. J., McWilliams, K. A., Fiori, R. A. D., Ponomarenko, P., and St.-Maurice, J.-P.: Improvement of SuperDARN velocity measurements by estimating the index of refraction in the scattering region using interferometry, Geophys. Res. Lett., 114, A07305, doi:10.1029/2008JA013967, 2009.

Gillies, R. G., Hussey, G. C., Sofko, G. J., Wright, D. M., and Davies, J. A.: A comparison of EISCAT and SuperDARN Fregion measurements with consideration of the refractive index in the scattering volume, Geophys. Res. Lett., 115, A06319, doi:10.1029/2009JA014694, 2010.

Greenwald, R. A., Baker, K. B., Dudeney, J. R., Pinnock, M., Jones, T. B., Thomas, E. C., Villain, J.-P., Cerisier, J.-C., Senior, C., Hanuise, C., Hunsuker, R. D., Sofko, G., Koehler, J., Nielsen, E., Pellinen, R., Walker, A. D. M., Sato, N., and Yamagishi, H.: DARN/SuperDARN: A global view of the dynamics of highlatitude convection, Space Sci. Rev., 71, 763-796, 1995.

Haldoupis, C., Nielsen, E., and Ierkic, H. M.: STARE Doppler spectral studies of westward electrojet radar aurora, Planet. Space Sci., 32, 1291-1300, 1984.

Haldoupis, C., Nielsen, E., and Schlegel, K.: Dependence of radar auroral scattering cross section on the ambient electron density and the destabilizing electric field, Ann. Geophysicae, 8, 195212, 1990.

Heinselman, C. J. and Nicolls, M. J.: A Bayesian approach to electric field and E-region neutral wind estimation with the Poker Flat Advanced Modular Incoherent Scatter Radar, Radio Sci., 43, RS5013, doi:10.1029/2007RS003805, 2008.

Huba, J. D., Ossakow, S. L., Satyanarayana, P., and Guzdar, P. N.: Linear theory of the $\boldsymbol{E} \times \boldsymbol{B}$ instability with an inhomogeneous electric field, J. Geophys. Res., 88, 425-435, 1983.

Kane, T. A., Makarevich, R. A., and Devlin, J. C.: HF radar observations of ionospheric backscatter during geomagnetically quiet periods, Ann. Geophys., 30, 221-233, doi:10.5194/angeo-30221-2012, 2012.

Keskinen, M. J.: Nonlinear theory of the $\boldsymbol{E} \times \boldsymbol{B}$ instability with an inhomogeneous electric field, J. Geophys. Res., 89, 3913-3920, 1984.

Kosch, M. J., Anderson, C., Yiu, H.-C. I., Kellerman, A. C., Makarevich, R. A., Aruliah, A., Conde, M., Griffin, E., Davies, T., McWhirter, I., and Dyson, P. L.: First observations of simultaneous inter-hemispheric conjugate highlatitude thermospheric winds, J. Geophys. Res., 115, A09328, doi:10.1029/2009JA015178, 2010.

Koustov, A. V., Sofko, G. J., André, D., Danskin, D. W., and Benkevitch, L. V.: Seasonal variation of HF radar F region echo occurrence in the midnight sector, J. Geophys. Res., 109, A06305, doi:10.1029/2003JA010337, 2004. 
Kustov, A. V., Uspenskii, M. V., and Williams, F. J. S.: Saturation effects of auroral-electrojet turbulence, Geom. Aeron., 28, 923927, 1988.

Linson, L. M. and Workman, J. B.: Formation of striations in ionospheric plasma clouds, J. Geophys. Res., 75, 3211-3219, 1970.

Lyons, L. R., Zou, S., Heinselman, C. J., Nicolls, M. J., and Anderson, P. C.: Poker Flat radar observations of the magnetosphereionosphere coupling electrodynamics of the earthward penetrating plasma sheet following convection enhancements, J. Atmos. Sol.-Terr. Phys., 71, 717-728, 2009.

Makarevich, R. A.: HF radar observations of high-velocity $E$-region echoes from the eastward auroral electrojet, J. Geophys. Res., 113, A09321, doi:10.1029/2008JA013204, 2008.

Makarevich, R. A.: On the occurrence of high-velocity E-region echoes in SuperDARN observations, J. Geophys. Res., 115, A07302, doi:10.1029/2009JA014698, 2010.

Makarevitch, R. A., Honary, F., and Koustov, A. V.: Simultaneous HF measurements of E- and F-region Doppler velocities at large flow angles, Ann. Geophys., 22, 1177-1185, doi:10.5194/angeo22-1177-2004, 2004.

Milan, S. E., Yeoman, T. K., Lester, M., Thomas, E. C., and Jones, T. B.: Initial backscatter occurrence statistics from the CUTLASS HF radars, Ann. Geophys., 15, 703-718, doi:10.1007/s00585-997-0703-0, 1997.

Ponomarenko, P. V. and Waters, C. L.: Spectral width of SuperDARN echoes: measurement, use and physical interpretation, Ann. Geophys., 24, 115-128, doi:10.5194/angeo-24-115-2006, 2006.

Rishbeth, H. and Williams, P. J. S.: The EISCAT ionospheric radar: The system and its early results, Q. J. R. Astron. Soc., 26, 478$512,1985$.
Ruohoniemi, J. M., Greenwald, R. A., Baker, K. B., Villain, J. P., and McCready, M. A.: Drift motions of small-scale irregularities in the high-latitude F region - An experimental comparison with plasma drift motions, J. Geophys. Res., 92, 4553-4564, 1987.

Schlegel, K.: Coherent backscatter from ionospheric E-region plasma irregularities, J. Atmos. Terr. Phys., 58, 933-941, 1996.

Tsunoda, R. T.: High-latitude F region irregularities - A review and synthesis, Rev. Geophys., 26, 719-760, 1988.

Vickrey, J. F. and Kelley, M. C.: The effects of a conducting E layer on classical $\mathrm{F}$ region cross-field plasma diffusion, J. Geophys. Res., 87, 4461-4468, 1982.

Villain, J. P., Hanuise, C., and Caudal, G.: A SAFARI-EISCAT comparison between the velocity of $\mathrm{F}$ region small-scale irregularities and the ion drift, Geophys. Res. Lett., 90, 8433-8443, 1985.

Xu, L., Koustov, A. V., Thayer, J., and McCready, M. A.: SuperDARN convection and Sondrestrom plasma drift, Ann. Geophys., 19, 749-759, doi:10.5194/angeo-19-749-2001, 2001.

Yeoman, T. K., Wright, D. M., Stocker, A. J., and Jones, T. B.: An evaluation of range accuracy in the Super Dual Auroral radar Network over-the-horizon HF radar systems, Radio Sci., 36, 801-813, 2001.

Yeoman, T. K., Chisham, G., Baddeley, L. J., Dhillon, R. S., Karhunen, T. J. T., Robinson, T. R., Senior, A., and Wright, D. M.: Mapping ionospheric backscatter measured by the SuperDARN HF radars - Part 2: Assessing SuperDARN virtual height models, Ann. Geophys., 26, 843-852, doi:10.5194/angeo26-843-2008, 2008. 